\title{
Só acredito lendo: resistência social em contos ilustrados para crianças
}

\section{Beatriz dos Santos Feres}

Docente da Universidade Federal Fluminense (UFF), Brasil beatrizferes@id.uff.br

Resumo: Neste trabalho, à luz da Teoria Semiolinguística de Análise do Discurso, objetiva-se identificar, no conjunto verbo-visual das obras Flicts, de Ziraldo (1999 [1969]), Romeu e Julieta, de Ruth Rocha (2009 [1977]), e Uma princesa nada boba, de Luiz Antônio (2011), estratégias de persuasão e sedução com vistas à adesão do leitor ao projeto de influência que as subjaz. Pressupõe-se que a combinação entre forma narrativa e função argumentativa permite a identificação do leitor com as personagens e com a dramaticidade de suas ações, favorecendo a persuasão projetiva ligada ao fazer crer, diferente do que ocorre na argumentação propriamente dita, considerada impositiva por explicar o porque e o como dos fatos, incluindo o outro em um esquema de verdade (CHARAUDEAU, 2004). Observam-se, no corpus, marcas textuais que materializam representações sociais (MOSCOVICI, 2015) e propiciam o espelhamento, a conformação social e a resistência ideológica.

Palavras-chave: Discurso. Persuasão Projetiva. Contos ilustrados. Semiolinguística.

\begin{abstract}
In this work, in light of the Semiolinguistic Theory of Discourse Analysis, we aim at identifying, in the verb-visual set of works Flicts, by Ziraldo (1999 [1969]), Romeo and Juliet, by Ruth Rocha (2009 [1977]) and A not-so-silly princess, by Luiz Antônio (2011), strategies of persuasion and seduction focusing on the reader's adherence to the influence project underlying them. It is assumed that the combination of narrative form and argumentative function allows the reader's identification with characters and with the dramaticity of their actions, favoring the projective persuasion linked to the make believe, different from what occurs in the argumentation itself, considered imposing, as it explains the why and how of facts, including the other in a truth scheme (CHARAUDEAU, 2004). In the corpus, textual marks that materialize social representations ( $\mathrm{MOSCOVICl}, 2015)$ and provide mirroring, social conformation and ideological resistance are observed.
\end{abstract}

Keywords: Speech. Projective Persuasion. Illustrated stories. Semiolinguistics. 


\section{Era uma vez uma tese vestida de figuras}

Neste artigo, partimos do pressuposto de que narrar convence, ainda que não seja por meio da imposição de ideias numa argumentação estrita, mas por meio de implícitos e de estratégias ligadas à narração.

Esse pressuposto mostra-se fortalecido quando se refere ao gênero textual mais conhecido, no Brasil, como livro ilustrado ("picturebook") entendido, aqui, como conto ilustrado, ou, mais especificamente, aquele constituído por signos verbais e visuais. Sendo a criança seu público leitor preferencial, parece-nos ainda mais relevante o potencial do conto ilustrado como representação social, ou como portador de representações sociais que, de um lado, participam da "tradição", mas que, de outro, por seu caráter persuasivo vinculado à "formação social" da criança, também podem constituir a "resistência" a valores e estereotipias - como tem se tornado cada vez mais comum no campo editorial brasileiro.

Em tempos de diferenças sociais tão bem marcadas - muitas vezes polarizadas -, mas, em contrapartida, de tantos movimentos sociais voltados para o respeito à diversidade e para o combate a estereótipos segregadores, a problematização acerca da resistência a valores consolidados enfatiza a ideia de que a sociedade pode "pensar", isto é, de que não é composta por "receptores passivos", mas por pessoas e grupos capazes de produzir representações e soluções para suas próprias questões, ao contrário de reproduzir e fazer reproduzir ideologias dominantes. A massificação comunicativa destes tempos e, sobretudo, a celeridade acentuada pelos meios virtuais, embora também sirvam para a expressão de universos consensuais, estimulam a reconstrução do senso comum e provam a dinamicidade das representações sociais, isto é, das formas intercambiáveis de compreender e de comunicar o que sabemos (MOSCOVICI, 2015).

Soma-se a essa ideia de resistência a noção de sujeito da linguagem na perspectiva da Teoria Semiolinguística de Análise do Discurso (CHARAUDEAU, 2008): um sujeito essencialmente ativo, seja como produtor, seja como receptor. Longe de ser concebido como um sujeito apenas “assujeitado", ele interage, influencia o outro e é influenciado por ele. Locutor e interlocutor, parceiros do "mundo social", afetados, sim, por crenças e valores, são potencialmente hábeis e reativos para resistir e propor novos olhares. 
Respaldam-se no consenso, porém agem por meio de estratégias discursivas; colocam-se e percebem como os outros se colocam. Sua interação se ajusta, por um lado, aos contratos comunicativos já referendados socialmente, num movimento de repetição de modelos textuais e de fórmulas comunicativas, e, por outro, num movimento de originalidade propiciado pelo ineditismo de cada enunciação, ou mesmo pela atitude criativa de certos pontos de vista. O sujeito da linguagem, portanto, se equilibra entre o consensual, ou o "tradicional", e o novo, o inédito, ou o "subversivo".

Numa generalização não muito arriscada, afirma-se então que, nos variados domínios discursivos, é possível verificar a atitude de resistência respaldada pela linguagem - ao que está posto por meio do "esticamento" daquilo que é consensual até que, (um tanto) rompido, surja uma nova maneira de compreender um fato, o mundo, as pessoas. Moscovici (2015) trata da ancoragem como processo de familiarização "de algo estranho e perturbador" a partir de paradigmas já conhecidos, e da objetivação como processo de geração de representações sociais baseado na "materialização de abstrações", ou melhor, na "transformação de uma representação na realidade da própria representação" (processo este quase sempre atribuído a filósofos, cientistas, políticos).

Assim, parece pertinente pensar num processo de delimitação de representações sociais acionado, indiretamente, nas figurativizações, nas narrativas, por meio de seus personagens, ações, tempo e espaço, que, em primeiro lugar, levam o leitor a ancorar o "estranho" ao experienciado, ou ao sabido, mas que também permitem objetivar uma ideia nova, um novo ponto de vista, ou algo quase indizível.

Nos casos em tela, a diversidade e o empoderamento, noções objetivadas pelas Ciências Humanas, chegam ao senso comum por meio de contos ilustrados, com a vantagem dos afetos e das inferências axiológicas acionadas pelas narrativas ${ }^{1 \mathrm{e}}$. Como o cientista, o "poeta" percebe algo quase indizível e

\footnotetext{
1 “O termo diversidade (Verschiedenheit [alemão]; Diversity [inglês], Diversité [francês], Diversità [italiano], etc.) designa, normalmente, a qualidade ou a condição do que é diverso, as características ou elementos diversos entre si, que existem sobre um assunto, ambiente, etc. Afirma-se que há, por exemplo, atualmente, uma diversidade de opiniões ou pontos de vista, diversidade de costumes, hábitos, comportamentos, crenças e valores, uma diversidade sexual, a diversidade biológica ou a biodiversidade, etc. [...] em Hegel, diversidade envolve tanto uma igualdade quanto uma desigualdade, que torna duas coisas tanto iguais quanto desiguais. Ora,
} 
concebe um meio para expressá-lo. Se o primeiro necessita da definição de um conceito e de um novo termo para nomeá-lo, o segundo usa jogos de linguagem e mostra figuras numa trama para representar um olhar sobre a vida - consensual, ou subversivo -, e levar o leitor a uma "conclusão avaliada".

Além dessa possível delimitação de representações sociais produzida indiretamente pela figurativização em narrativas, parece relevante para a problematização aqui proposta refletir acerca da intenção de um fazer crer que subjaz majoritariamente as histórias, sobretudo as direcionadas às crianças. Não nos referimos aqui ao princípio de verossimilhança igualmente explorado nos gêneros ficcionais de base narrativa, e sim às estratégias de persuasão e de sedução utilizadas na construção textual com a finalidade de conquistar a adesão do leitor ao projeto de influência que exala do texto.

Em narrativas, essas estratégias permitem tornar implícita a defesa de uma tese sob a roupagem de um enredo que não só capta a identificação do interlocutor numa atitude projetiva, mas também o convence por causa dessa mesma identificação. A construção textual é preparada para expor dramaticamente fatos, situações, relações pessoais, para que o sujeito interpretante seja não somente afetado pela patemização programada na textualização, mas, indiretamente, convencido de uma ideia, ou ainda levado a agir de uma determinada maneira.

Em conformidade com essa ideia, este trabalho, fundamentado principalmente pela Teoria Semiolinguística de Análise do Discurso, tem como objetivo identificar estratégias de persuasão e de sedução com vistas à adesão do leitor ao projeto de influência que subjaz as obras Flicts, de Ziraldo (1999 [1969]), Romeu e Julieta, de Ruth Rocha, com ilustrações de Mariana Massarani (2009 [1977]), e Uma princesa nada boba, de Luiz Antônio, com ilustrações de Biel Carpenter (2011).

diversidade congrega 'a igualdade e a desigualdade de um terceiro, um outro, enquanto elas mesmas são"'. (KONZEN, 2012, p. 41)

2 Segundo Baquero (2012, p. 175, 176 e 180), “empowerment é um conceito que tem raízes na Reforma Protestante. Contemporaneamente, se expressa nas lutas pelos direitos civis, no movimento feminista e na ideologia da "ação social", presentes nas sociedades dos países desenvolvidos, na segunda metade do século XX. Nos anos 70, esse conceito é influenciado pelos movimentos de auto-ajuda, e, nos 80, pela psicologia comunitária. Na década de 1990, recebe o influxo de movimentos que buscam afirmar o direito da cidadania sobre distintas esferas da vida social, entre as quais a prática médica, a educação em saúde, a política, a justiça, a ação comunitária. [...] Freire propõe outra concepção de empowerment, não individual, nem comunitário, nem meramente social, mas um conceito de empowerment ligado à classe social." 


\section{A persuasão projetiva}

Em “A argumentação talvez não seja o que parece ser”, Charaudeau (2004) expõe o caráter complementar entre a atitude de argumentar, essencialmente impositiva, e a de narrar, fundamentalmente projetiva. Segundo ele, para quem defende que tudo é argumentação, todo enunciado, inclusive o narrativo, guardaria uma orientação argumentativa, pois é passível de suscitar perguntas como "por que ele disse isso?" ou "por que disse isso assim?". Já para quem defende que tudo é narração, a linguagem se prestaria principalmente a descrever "uma busca, a do destino humano" (Idem) e a argumentação serviria como apoio a essa descrição.

Em cada uma dessas posições, uma atitude dominaria a outra, contudo, na argumentação, a explicação do porquê e do como dos fatos obrigaria o outro a se incluir num certo esquema de verdade - e, por isso, a argumentação é considerada impositiva. Já a descrição das qualidades dos seres do mundo e de suas ações, própria da narração, não se impõe ao outro; ao contrário, propõe-lhe "uma trama narrativa do mundo do qual ele pode fazer parte" (Idem, p. 34, grifo nosso), permitindo ao outro se identificar com as personagens e com suas ações - e, por essa razão, a narração é considerada projetiva.

Dentre outros aspectos, Charaudeau (2004) trata, de um lado, da explicitude do texto reconhecidamente argumentativo - relacionada à presença de marcas específicas, ou de certo tipo de construção frástica - e, de outro, da organização persuasiva implícita observada, por exemplo, em um testemunho, que, sendo uma mininarrativa, pode preencher de "carga semântica" argumentos da cadeia de raciocínio. O testemunho, ao apresentar essa finalidade, passa a ter estatuto de prova que se vincula à situação comunicativa em que se insere.

Soma-se a isso a prerrogativa, postulada pela Semiolinguística, de que todo ato de linguagem é regido pela situação comunicativa e por seus componentes (identidade do sujeito responsável pelo ato, sua intencionalidade, o propósito temático e as circunstâncias materiais em que ele se encontra), isto é, em certas circunstâncias, uma "roupagem" narrativa pode se tornar a melhor estratégia argumentativa. Essa prerrogativa parece ganhar relevo ainda mais acentuado quando o ato de linguagem se direciona a 
crianças e é organizado com uma intenção "formativa”, isto é, quando pretende (também) "ensinar" um modo de ser e de olhar o mundo, como é prevalente em narrativas para a infância.

Ainda quanto à finalidade argumentativa das narrativas, vale citar a diferenciação proposta por Fiorin para as operações de tematização e de figurativização (FIORIN, 2008, p. 32-33), que "desvelam os valores, as crenças, as posições do sujeito da enunciação". A primeira produz textos considerados mais "temáticos", que pretendem "explicar o mundo", geralmente usando muitos termos abstratos; já a segunda, mais concretos, utilizando personagens, ambientes, explicitação de tempos decorridos, ações, para “criar um simulacro do mundo". Por exemplo, uma fábula demonstra atitudes relacionadas a um ensinamento, e seus personagens, quase sempre, são animais que desempenham ações humanas. Em geral, conjugada à fábula, a "moral da história" costuma explicitar esse ensinamento, num enunciado curto, quase sempre temático.

Como exemplo disso, Platão e Fiorin (1997, p. 87-89) utilizam a fábula “O escorpião e o sapo": o sapo carrega o escorpião nas costas para salvá-lo da água; mesmo assim, picado por ele, ambos afundam. Ao final, explica-se: "Cada ser humano tem uma índole, uma propensão natural, e ela não muda, manifesta-se em todas as circunstâncias da vida, até mesmo quando essa manifestação contraria o bom senso". Com esse conjunto, os autores conseguem demonstrar como os textos figurativos têm a função representar o mundo, criando um efeito de realidade, e os temáticos, a função de interpretar o mundo, fazendo comentários sobre ele.

Mesmo que um texto figurativo (nos termos mencionados) não venha acompanhado de uma "moral", como ocorre com as fábulas, há uma tese implícita que se depreende da trama (a escola diria: “uma mensagem”) e, por esse motivo, serve para incutir ideias. Sobretudo em relação à literatura destinada à infância, parece pertinente ressaltar que, desde seu nascedouro, o caráter "exemplar" das narrativas serviu como critério para compilações de textos orais com viés formativo, como se observa desde a Idade Média (MEIRELES, 1984). Coelho (2000, p. 15) chega a afirmar que "a literatura, em especial a infantil" [...] tem "uma tarefa fundamental a cumprir nesta 
sociedade em transformação: a de servir como agente de formação" [...] “...da consciência de mundo das crianças e dos jovens".

Embora esse caráter "utilitário" atribuído à Literatura Infantil seja altamente questionável e pareça se sobrepor, muitas vezes, à natureza artística das obras (não cabe aqui essa problematização), há narrativas, produzidas na contemporaneidade, de excelente qualidade estética, que interessam também às crianças e que, se não apresentam de modo saliente esse viés didático, estão igualmente impregnadas, como todo bem cultural, de forte função axiológica.

É isso que se pode observar em Flicts (ZIRALDO, 1999 [1969]), Romeu e Julieta (ROCHA, 2009 [1977]), e Uma princesa nada boba (ANTÔNIO, 2011). São narrativas de conformação verbo-visual direcionadas preferencialmente às crianças, que trazem uma intencionalidade argumentativa, voltadas para a persuasão acerca do tema comum da aceitação da diversidade.

Cada uma apresenta argumentos por meio da descrição de fatos e ações, os quais permitem a identificação do leitor e sua adesão à proposta temática. Ao viver simbolicamente a segregação, as personagens mostram os sentimentos de quem é rejeitado socialmente, além de permitir uma tomada de posição por parte do leitor quanto à ação mesma de rejeitar o desigual. 0 leitor se projeta na narrativa e sai de lá persuadido acerca da tese defendida.

Esse movimento persuasivo será examinado com mais detalhe na próxima seção.

\section{Narrar para convencer}

Para comprovar a persuasão projetiva característica de narrativas, aqui serão explorados aspectos de três contos ilustrados, cujo propósito comum pode ser resumido em "resistência ao desrespeito à diversidade", produzidos no intervalo de mais de quarenta anos. O primeiro deles é considerado um "clássico" com mais de cinquenta edições desde 1969 e várias traduções: Flicts (ZIRALDO, 1996 [1969]).

Ao lançar Flicts, em 1969, Ziraldo talvez não previsse a revolução que provocava na ilustração de livros infantis brasileiros. Naquela obra, as imagens, não figurativas, não correspondem a um ornamento do texto, complementando as informações escritas; pelo contrário, as cores é que falam, competindo à 
expressão verbal esclarecer o assunto e explicar o conflito, vivenciado pelo herói, ele mesmo um pigmento que não encontra lugar no universo dos tons pictóricos. (ZILBERMAN, 2014, p. 159)

É a história de uma cor diferente, solitária, em busca de um lugar que lhe é negado no mundo: "Era uma vez uma cor/muito rara e muito triste/que se chamava Flicts. [...] Era apenas/o frágil e/feio e aflito/Flicts" (ZIRALDO, 1996 [1969], p. 5 e 11). A personificação fica toda a cargo de cores, porém, além de Flicts, as outras cores com quem interage aparecem instaladas em seus devidos suportes: bandeiras, caixas de lápis de cor, semáforos etc., exceto Flicts. Não encontrando um lugar para si neste mundo, ela parte e descobre que a Lua é Flicts.

A expressão da discriminação e do sentimento de exclusão não ocorre somente por meio das palavras: Flicts é representado sempre ocupando pouco espaço das páginas em relação às outras cores e isolado delas por intervalos sem cor. No dia em que Flicts desiste de procurar, uma linha de sua cor é colocada na vertical, sozinha, na parte direita da página dupla. Na página seguinte, a faixa flicts se esmaece até desaparecer na parcela inferior da folha.

Nesse caso, mostra-se a discriminação da diversidade na perspectiva de uma personagem-cor que age como criança: "Um dia ele viu no céu/ depois da chuva Cinzenta/ a turma toda feliz/saindo para o recreio/e se chegou para brincar" (ZIRALDO, 1996, p. 16). Com isso, a adesão, por parte da criançaleitora, ao sujeito-destinatário programado na textualização, é facilitada. Com a adesão, a projeção de reações afetivas em relação à situação vivida por Flicts (seja quanto à personagem que sofre, seja quanto às que a fazem sofrer) permite a compreensão "virtual" da discriminação, e, provavelmente, aversão a ela, em virtude do sofrimento. Um fazer sentir, fundado na provável identificação do leitor ao projeto de sedução, está a serviço do fazer crer. A narrativa, assim, incita, com grande chance de sucesso, a tomada de posição ao leitor a favor da tese defendida. Pignatari explica o "atrativo" oferecido pela prosa de ficção (aqui estendido para o conto ilustrado) para a inevitável "conclusão":

Na prosa de ficção, aparentemente, a palavra leva e se deixa levar; só que, à beira da conclusão, deixa o leitor na mão. A conclusão é o livro inteiro. Onde só parecia haver enunciado, só há enunciação: o signo verbal que parecia vidro transparente para a visão plena de um objeto ou referente externo se transforma em espelho, ou em régua, que, para medir o espaço, tem de 
acompanhá-lo. O que é diferente de uma tabuada. A prosa de ficção é contra a "maldita mania de querer concluir", no dizer de Flaubert, ao mesmo tempo que, sedutora, parece oferecer todos os atrativos das conclusões, ou de uma conclusão. Que é quando o leitor habitual pergunta: Que é que o autor quis dizer com isso?... (PIGNATARI, 1995, p.79)

Em Flitcs, a sensação de ser segregado está representada na história dessa cor "diferente" e referenda a conclusão de que a segregação social é abominável: se excluir alguém traz sofrimento e afasta o "diferente" do convívio, então não se deve fazê-lo. Já que "o aspecto argumentativo de um discurso encontra-se frequentemente no que está implícito" (CHARAUDEAU, 2008, p. 204), as narrativas parecem guardar um importante potencial persuasivo. Nelas, observa-se a relação triangular própria da argumentação: o sujeito argumentante (papel assumido pelo enunciador-narrador) se engaja em relação a um questionamento e desenvolve um raciocínio (a história de Flicts) para tentar estabelecer uma verdade; há uma proposta sobre o mundo que provoca questionamento quanto à sua legitimidade (não é ético discriminar o "diferente"), e um sujeito que constitui o alvo dessa argumentação (o leitorcriança). Embora de modo implícito, o questionamento e a persuasão do interlocutor estão em curso ao longo da narração.

Também em Romeu e Julieta (ROCHA, 2009), as cores são exploradas em função do questionamento que subjaz a narrativa, a aceitação da diversidade como resistência à discriminação social - como em Flicts -, entretanto, a proposta persuasiva recebe uma configuração mais alegre, divertida, com uma figurativização mais próxima à das fábulas: na edição mais recente de 2009, as personagens são ilustradas como borboletas, mas com corpo e vestimenta de "gente" - além do personagem Ventinho, um menino que voa com um motor com hélices acoplado às costas e apresenta Julieta a Romeu. Como na trama shakespeariana evocada por seus nomes, a aproximação das criançasprotagonistas é proibida: elas pertencem a canteiros diferentes - um é azul; o outro, amarelo. Os protagonistas subvertem a ordem quando, além de se tornarem amigos, perdem-se, distraídos com as brincadeiras, provocando, com isso, a união das borboletas de ambos os canteiros para encontrá-los. A partir da experiência positiva de mistura das borboletas de cores diferentes na busca pelas crianças, todos passaram a viver juntos, sem mais segregação.

Tanto quanto Flicts, Romeu e Julieta é um conto que expõe o problema social da (não) aceitação do diferente e propõe a subversão de alguns valores 
relacionados a regras de comportamento. Na primeira narrativa, Flicts só encontra um lugar em outro mundo, depois de não obter sucesso em suas tantas tentativas de entrosamento; já Romeu e Julieta se engajam na resistência a uma regra que, como provaram, não se sustentava. Considerando-se as datas de suas primeiras publicações, parece permitido inferir que, em 1969, no auge da ditadura brasileira, Ziraldo retrata a dureza das relações humanas no que respeita à prevalência do status quo, da insensibilidade a respeito daquele que, “diferente”, é isolado do convívio. Já em 1977, ainda sob a censura dos meios de comunicação e, portanto, dependente das metáforas para defesa de uma posição, as diferenças sociais são tratadas em sua base, isto é, a partir de como agem os indivíduos, aceitando ou rompendo com as injustificáveis regras impostas. Como se constata, ambas as narrativas são convites à reflexão - e não mero entretenimento infantil.

Muitos outros contos ilustrados poderiam ser mencionados por atenderem aos mesmos objetivos. Em virtude deste curto espaço de discussão, porém, cita-se apenas mais um, publicado mais recentemente: Uma princesa nada boba (ANTONIO, 2011). Com a temática igualmente relacionada à resistência à exclusão, porém com uma proposta mais incisiva e atual combate à discriminação racial e empoderamento da mulher negra -, parece evidente o emprego do procedimento discursivo-argumentativo da "descrição narrativa", ou seja, da história contada para reforçar uma prova ou para produzi-la (CHARAUDEAU, 2008).

O título já traz pressuposto que há princesas bobas e o subentendido de que a protagonista, embora também princesa, não é nada boba. As primeiras frases do texto - "Por que eu não podia ser igual a uma princesa? Só queria que alguém me explicasse" (ANTONIO, 2011, p. 2) - colocam em questão a Proposta da argumentação: meninas negras também podem ser princesas? Queixosa por destoar do modelo estabelecido socialmente - "Cachinhos dourados. Longos fios escorridos. Narizinho pontudo" (p. 10) -, a protagonista usa um nome falso, Stephanie, com $\mathrm{PH}$, e intenta "ser igual a uma princesa": "Quero voltar para a escola com cabelo de princesa, rosto de princesa, roupa de princesa" (p. 18). 
Nas ilustrações, a menina aparece de costas, ou parcialmente ocultada pelas margens das páginas, ou escondida embaixo de um guarda-chuva. Ao passar as férias no sítio da avó, encontra, no rio, uma moça muito bonita, que Ihe oferece um abebé (um espelho) e Ihe conta histórias de princesas inteligentes e fortes, que fogem do estereótipo assimilado socialmente. A moça falou de Oyá, princesa nigeriana que viveu por volta de 1400 a.C. e que virava búfalo quando queria, e de Nzinga Mbandi, princesa angolana nascida em 1852, que conseguiu a aliança de vários reinos para lutar contra a invasão portuguesa. Também falou da tataravó da menina, igualmente princesa, que resistiu à escravidão na Bahia. Para sua surpresa, nenhuma dessas princesas ficara chorando à espera de um príncipe, como seria de se supor em função da ideia de "princesa" perpetuada até então. Depois dessa revelação, a imagem da protagonista aparece ilustrada por inteiro, de frente, acompanhada da frase "Sou uma princesa", revelando sua autoaceitação e seu empoderamento. Nas últimas frases do conto, lê-se: "Eu me chamo Odara. Nome de princesa nada, nada boba” (ANTONIO, 2011, p. 52).

Considerando-se que a lógica argumentativa prevê uma asserção de partida, uma de chegada e pelo menos uma de passagem, é possível verificar, nessa narrativa, que se parte da premissa (asserção de partida) de que meninas negras também são princesas - a despeito de a representação vigente nas sociedades ocidentais não costumar incluir princesas negras para chegar à conclusão (asserção de chegada) de que a protagonista também pode ser considerada uma princesa (ou qualquer menina negra com quem se possa identificar a protagonista). Como asserção de passagem, apresenta-se o protagonismo das princesas africanas descritas na narrativa, exemplos de "outro tipo de princesa", mais corajosas e independentes do que o modelo estereotipado. Essas descrições funcionam como provas, como argumentos que incitam o interlocutor (seja a "princesa" Odara, seja o leitor, de forma indireta) a aceitar a proposta como verdadeira.

Aqui se tomam emprestadas novamente as noções de ancoragem e de objetivação como propostas por Moscovici (2015) para, aplicadas à análise dessas narrativas, serem associadas à apreensão das representações sociais da diversidade e do empoderamento. Tão bem ajustadas à ideia de resistência, essas noções, relativamente recentes em nossas sociedades, têm sido utilizadas nos processos de formação das condutas e de orientação das 
comunicações sociais - seja nas recorrentes campanhas de conscientização realizadas por grupos de defesa direitos sociais, por exemplo, seja na educação das crianças.

Observando-se a existência de um universo consensual crente na segregação de grupos de acordo com o estabelecido como verdade, essas narrativas surgem como sugestões de pontos de vista que subvertem o senso comum, numa atitude de resistência, afinal, "existe uma necessidade contínua de reconstruir o 'senso comum' ou a forma de compreensão que cria o substrato das imagens e sentidos, sem a qual nenhuma coletividade pode operar" (MOSCOVICl, 2015, p. 48). Nelas, ideias se materializam em tramas reconhecíveis a partir de elementos do universo da criança (claro, dos adultos também), acionando a memória e as categorias ali armazenadas, até que se chegue ao conhecimento "assistido" de uma nova representação, ou de uma nova perspectiva, que, aos poucos, a partir da interação entre os indivíduos, possa ser aceita como senso comum.

\begin{abstract}
Ancoragem e objetivação são, pois, maneiras de lidar com a memória. A primeira mantém a memória em movimento e a memória é dirigida para dentro, está sempre colocando e tirando objetos, pessoas e acontecimentos, que ela classifica de acordo com um tipo e os rotula com um nome. A segunda, sendo mais ou menos direcionada para fora (para outros), tira daí conceitos e imagens para juntá-los e reproduzi-los no mundo exterior, para fazer as coisas conhecidas a partir do que já é conhecido. (MOSCOVICl, 2015, p, 78)
\end{abstract}

Em Flicts, a dupla antagônica "exclusão versus inclusão" se ancora na experiência da personagem-cor, não aceita por ser diferente. É preciso reconhecer a personificação das cores, a semelhança entre suas atitudes e as das crianças, os tantos elementos do mundo tornados atores da trama. $\mathrm{Na}$ inferência-conclusão de que é abominável excluir, pode-se levar o leitor ao conhecimento, com a devida avaliação, da diversidade, inserida em uma proposta de aceitação. Eis então uma representação social que, embora arraigada nas Ciências Humanas (sobretudo), se não era antes tão bem delimitada para o senso comum, agora já apresenta contornos e pode ser nomeada.

Da mesma maneira, em Romeu e Julieta, ancora-se, no intertexto e no movimento de aproximação e de estabelecimento de relações de amizade vivido pelas personagens-borboletas de cores diferentes, a discriminação 
nascida do preconceito que repele o desigual. Implicitamente, conduz-se o leitor, mais uma vez, à consciência da diversidade, sendo possível afirmar: esse conto trata do combate à discriminação.

Por fim, em Uma princesa nada boba, induz-se o leitor à consciência do empoderamento da mulher negra, respaldado pela ancoragem permitida pela história-alegoria de Odara, menina que descobre "outro tipo de princesa" com que se identifica, renovando a ideia preconcebida.

\section{Só acredito lendo}

A reflexão acerca da potencialidade das narrativas quanto à persuasão e à disseminação de ideias e valores contou, neste trabalho, com a análise de textos configurados de acordo com o modo narrativo de organização do discurso que trazem implícita uma intencionalidade argumentativa. Em outras palavras, contos ilustrados foram selecionados como objeto de análise a fim de se mostrar como narrativas materializam representações sociais e podem ser coadjuvantes na reconstrução de conceitos e na alimentação do senso comum a partir de uma argumentação revestida de figurativizações.

Nessa direção, pressupõe-se que contar uma história é mais do que divertir ou distrair uma criança; é fazer crer em ideias e valores - ainda que subliminarmente. Narrativas preenchem semanticamente argumentos e reforçam tomadas de posição e, no recorte problematizado, contam com um movimento lúdico e de fácil captação do leitor. Quando apresentados revestidos de elementos de identificação imediata (personagens-crianças, contextos da infância, atividades realizadas pelos pequenos), os propósitos são absorvidos pelos sentidos todos, permeados por afetos e por decisões internas calcadas em avaliações incitadas pelas tramas.

Para as crianças, uma narrativa também pode se transformar em um meio de representar um sentimento ou uma ideia que, para elas, podem ser inéditos, complexos, de conscientização elaborada. De certa maneira, ao dar forma a algo percebido, mas não conscientemente delimitado pela criança, a leitura de um conto pode tornar-se um instrumento de objetivação, mesmo que "assistida", conduzida pela mediação de adultos (seja na sua produção, seja na escolha do conto, seja na leitura partilhada) que já dominavam determinada representação social e desejaram incluí-la no universo infantil. 
As representações permeiam todas as interações sociais e moldam olhares, sentires, fazeres. No que respeita aos bens culturais de acesso preferencial das crianças, como os “picturebooks", ou contos ilustrados, a escolha do olhar que a elas se oferece é um problema diretamente ligado à formação de novas gerações: à perpetuação de velhos valores, ou à reflexão e à renovação de visões do mundo, numa atitude de resistência social. É uma escolha política, nada ingênua, que ajuda a criar redes sociais mais ou menos tolerantes e éticas.

\section{Referências}

ANTONIO, Luiz. Uma princesa nada boba. Ilustração: Biel Carpenter. São Paulo: Cosac Naify, 2011.

BAQUERO, Rute Vivian Angelo. A situação das Américas: democracia, capital social e empoderamento. Revista Debates, Porto Alegre, v. 6, n. 1, p. 173-187, jan.abr, 2012.

CHARAUDEAU, Patrick. A argumentação talvez não seja o que parece ser. In: GIERING, Maria Eduarda; TEIXEIRA, Marlene. Investigando a linguagem em uso: estudos em Linguística Aplicada. São Leopoldo: Ed.Usininos, 2004. p. 33-44.

. Linguagem e discurso: modos de organização. Coordenação da tradução:

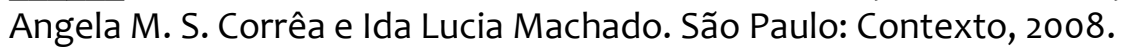

COELHO, Nely Novaes. Literatura infantil: teoria, análise, didática. São Paulo: Moderna, 2000.

FIORIN, José Luiz. Em busca do sentido: estudos discursivos. São Paulo: Contexto, 2008.

FIORIN, José Luiz; Francisco PLATÃO. Lições de texto: leitura e redação. 2.ed. São Paulo: Ática, 1997.

KONZEN. Paulo Roberto. Conceito de Diversidade (Verschiedenheit) na Ciência da Lógica e na Filosofia do Direito de Hegel. Revista Eletrônica Estudos Hegelianos, ano 9, n. 17, p. 39-60, dez.2012.

MEIRELES, Cecília. Problemas de Literatura Infantil. 3.ed. Rio de Janeiro: Nova Fronteira, 1984 . 
MOSCOVICI, Sergei. Representações sociais: investigações em Psicologia Social. 11.ed. Ed. em inglês por Gerard Duveen. Trad. Pedrinho A. Guareschi. Petrópolis, RJ: Vozes, 2015.

PIGNATARI, Décio. Letras, artes, mídia. São Paulo: Ed. Globo, 1995. p.77-79

ROCHA, Ruth. Romeu e Julieta. Ilustr. Mariana Massarani. São Paulo: Salamandra, 2009 [1977].

ZILBERMAN, Regina. A literatura infantil brasileira. Ed. rev. e ampl. Rio de Janeiro: Objetiva, 2014.

ZIRALDO. Flicts. 30. ed. São Paulo: Melhoramentos, 1999 [1969].

\section{Forma de citação sugerida}

FERES, Beatriz dos Santos. Só acredito lendo: resistência social em contos ilustrados para crianças. EID\&A - Revista Eletrônica de Estudos Integrados em Discurso e Argumentação, Ilhéus, n. 19, v. 2, p. 18-32, dez.2019. DOI 10.17648/eidea-19-v2-2348. 